\title{
Transgenerational effect of UV-B priming on photochemistry and associated metabolism in rice seedlings subjected to PEG-induced osmotic stress
}

\author{
A. SEN ${ }^{*}$, J.T. PUTHUR ${ }^{*,+}$, D. CHALLABATHULA ${ }^{* *}$, and M. BRESTIC $\check{C}^{* * *, \#,+}$ \\ Plant Physiology and Biochemistry Division, Department of Botany, University of Calicut, C.U. Campus P.O., \\ 673635 Kerala, India* \\ Department of Life Sciences, School of Life Sciences, Central University of Tamil Nadu, Thiruvarur, 610004 Tamil \\ Nadu, India* \\ Department of Plant Physiology, Slovak University of Agriculture, Nitra, Slovak Republic ${ }^{* * *}$ \\ Department of Botany and Plant Physiology, Faculty of Agrobiology, Food, and Natural Resources, \\ Czech University of Life Sciences, 16500 Prague, Czech Republic ${ }^{\sharp}$
}

\begin{abstract}
Rice being the major food crop for more than half of the world population is severely affected by drought stress starting from the establishment of the seedling. We focused on the UV-B priming mediated transgenerational drought tolerance of a drought-tolerant rice variety (Vaisakh) towards polyethylene glycol (PEG) 6,000 (20\%)-induced drought. Results showed that priming in $\mathrm{F}_{0}$ generation and re-priming in $\mathrm{F}_{1}$ generation with UV-B enhanced the PEG stress tolerance potential of rice seedlings with increased expression of genes encoding antioxidant enzymes and stress-related proteins offering better protection to primed plants. UV-B priming maintained oxidative homeostasis of the plant cell thus ensuring uninterrupted mitochondrial and photosynthetic activities. Cumulatively, our results suggest that the transgenerational priming memory retained in the seeds is transferred to offspring without any loss. Moreover, re-priming in $\mathrm{F}_{1}$ generation further boosted the innate tolerance potential of a tolerant variety resulting in stable cellular redox homeostasis.
\end{abstract}

Keywords: mitochondria activity; Oryza sativa; photosynthetic machinery; priming memory; stress proteins.

\section{Introduction}

Rice (Oryza sativa) is a monocotyledonous model plant and is the most important food crop. Enhancing rice

\section{Highlights}

- Rice is a drought-sensitive crop

- UV-B priming maintained oxidative homeostasis

- Priming improved photosynthetic activities production has a critical role in the improvement of economic status in developing countries of Asia and Africa (Macovei et al. 2014). Drought is a main abiotic stress factor that can limit plant growth and development thereby

Received 16 September 2021

Accepted 8 February 2022

Published online 4 March 2022

${ }^{+}$Corresponding authors

e-mail: jtputhur@yahoo.com marian.brestic@uniag.sk

Abbreviations: $C_{\mathrm{i}}$ - intercellular $\mathrm{CO}_{2}$ concentration; $E$ - transpiration rate; $\mathrm{F}_{\mathrm{K}} / \mathrm{F}_{\mathrm{J}}$ - indicator of inhibition of electron donation by oxygenevolving complex; $\mathrm{F}_{\mathrm{m}}$ - maximal fluorescence; $g_{\mathrm{s}}$ - stomatal conductance; $\mathrm{PI}_{(\mathrm{abs})}$ - performance index; $P_{\mathrm{N}}-$ net photosynthetic rate; ROS - reactive oxygen species; $\mathrm{V}_{\mathrm{J}}$ - relative variable fluorescence at $\mathrm{J}$ step; $\Phi \mathrm{E}_{0}$ - electron transport quantum yield.

Acknowledgments: Akhila Sen is indebted to the Council of Scientific \& Industrial Research (CSIR), New Delhi, for the financial assistance through the award of Junior Research Fellowship (SRF). The authors extend their sincere thanks to the Department of Science \& Technology (DST), Government of India for granting funds under the Fund for Improvement of S\&T Infrastructure (FIST) program (DST-FIST/15-16/28.05.2015). The Regional Agricultural Research Station (RARS) Pattambi, Kerala, India, is gratefully acknowledged for providing seeds of rice.

Conflict of interest: The authors declare that they have no conflict of interest. 
crop yield (Seleiman et al. 2021). Since rice is extremely sensitive to drought stress and traditional agricultural practices are not sufficient to meet the requirements of an ever-growing world population, alternative methods for improving the growth and productivity of rice plants under drought stress conditions are required (Sen and Puthur 2021).

Drought stress has an impact on morphological, physiological, biochemical, and molecular responses in plants. Drought stress interrupts the photosynthetic mechanism and increases the photorespiration rate resulting in the enhanced production of reactive oxygen species (ROS) (Kaur and Asthir 2017). Increased ROS contents cause oxidative stress at the cellular level and cause membrane damage, protein oxidation, and DNA alterations ultimately leading to necrosis and cell death (Halliwell and Gutteridge 2015). It was reported that drought stress results in the increased production of hydrogen peroxide $\left(\mathrm{H}_{2} \mathrm{O}_{2}\right)$ and causes lipid peroxidation in rice. This leads to worse germination indices, seedling growth, and establishment as well reduced water content and photosynthetic rate in rice plants (Sohag et al. 2020). The productivity of crop plants is dependent on their water availability and water-use efficiency (Vozhehova et al. 2020). Sustaining crop productivity and yield even under less favorable environments is a constant challenge for plant breeders (Begcy et al. 2019).

Seed priming is an effective and simple technique to impart stress tolerance in plants. Seed priming increases the rate, percentage, and uniformity of germination even when the environmental conditions are unfavorable (Sen and Puthur 2020). Seed priming induces the synthesis of ROS-detoxifying enzymes, such as superoxide dismutase (SOD), catalase (CAT), ascorbate peroxidase (APX), and guaiacol peroxidase (GPX) which impart abiotic stress tolerance (Pradhan et al. 2020). It was reported that low doses of UV-B (ultraviolet B) cause stimulatory effects on plant growth and this phenomenon is called hormesis (Calabrese 2002). Our earlier study has revealed that pretreatment of rice seeds with UV-B enhances the innate tolerance potential of rice seedlings subjected to PEG stress. This is due to the enhanced production of osmolytes, enzymatic and nonenzymatic antioxidants, and also by increased relative gene expression of antioxidant enzymes and stress-related proteins. Therefore UV-B priming can be adopted for further enhancement of tolerance potential in a tolerant variety (Sen et al. 2021). The transgenerational retention of priming memory has great importance and scope in the area of agriculture. Transgenerational stress memory can contribute to the adaptation of a plant at different stages of its growth and can even be extended to the offspring (Crisp et al. 2016).

The current study was carried out to analyze the transgenerational effect of UV-B priming on abiotic stress tolerance of a tolerant variety (Vaisakh) subjected to polyethylene glycol-6,000 (PEG-6,000)-induced drought, by analyzing the biochemical, photosynthetic, and molecular changes in rice seedlings that emerged from primed and non-primed seeds.

\section{Materials and methods}

Plant material and growth conditions: The study was carried out in Oryza sativa var. Vaisakh (drought-tolerant). Seeds were collected from the Regional Agricultural Research Station (RARS) Pattambi, Kerala, India. Surface-sterilized seeds were subjected to UV-B priming $\left(2.5 \pm 0.29 \mathrm{~W} \mathrm{~m}^{-2}\right)$ for $20 \mathrm{~min}$. This intensity of UV-B irradiation was equivalent to a UV-B dose of $4 \mathrm{~kJ} \mathrm{~m}^{-2}$. The biologically effective UV-B (UV-BBE) was attained through normalization at $300 \mathrm{~nm}$; this was calculated according to Caldwell (1971). UV-B tubes (20 W, Philips, Germany) were covered with cellulose diacetate filters (Johnston Industrial Plastics, Toronto, Canada) to remove all incident UV-C. Rice plants were grown at a temperature of $29 \pm 3^{\circ} \mathrm{C}$, the light intensity of $1,300 \pm 320 \mu \mathrm{mol}$ (photon) $\mathrm{m}^{-2} \mathrm{~s}^{-1}$, relative humidity of $60 \pm 5 \%$, and 14/10-h regime in the greenhouse of the Department of Botany, University of Calicut, Kerala, India. Seeds were sown in pots containing solar-sterilized soil to which NPK was applied at regular intervals to ensure better growth. The seeds were collected from plants that emerged from the control $(\mathrm{C})$ and UV-B ( $\left.\mathrm{F}_{0} \mathrm{Pr}\right)$-primed seeds. Seeds collected from UV-B $\left(\mathrm{F}_{0} \mathrm{Pr}\right)$-primed plants were re-primed with UV-B $\left(\mathrm{F}_{1} \mathrm{Pr}\right)$ and were grown in separate culture bottles containing absorbent cotton soaked with double distilled water (control) and 20\% PEG-6,000 (osmolality

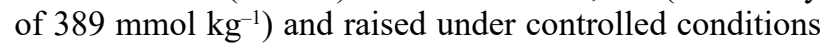
in a plant growth chamber having temperature of $24 \pm 2{ }^{\circ} \mathrm{C}$, light intensity of $300 \mu \mathrm{mol}$ (photon) $\mathrm{m}^{-2} \mathrm{~s}^{-1}$, and relative humidity of $55 \pm 5 \%$ with a $14 / 10$-h photoperiod. The different analyses were performed $9 \mathrm{~d}$ after germination.

\begin{tabular}{ll}
\hline Treatment & \\
\hline $\mathrm{C}$ & $\begin{array}{l}\text { control } \\
\text { seeds collected from the UV-B-primed plants grown } \\
\text { without any stress } \\
\text { seeds collected from the UV-B-primed plants } \\
\text { re-primed with UV-B and grown without any stress } \\
\mathrm{F}_{1} \mathrm{Pr}\end{array}$ \\
$\mathrm{P}$ & $\begin{array}{l}\text { seeds subjected to PEG stress } \\
\text { seeds collected from the UV-B-primed plants } \\
\mathrm{P}+\mathrm{F}_{0} \mathrm{Pr}\end{array}$ \\
$\mathrm{P}+\mathrm{F}_{1} \mathrm{Pr}$ & $\begin{array}{l}\text { subjected to PEG stress } \\
\text { seeds collected from the UV-B primed plants } \\
\text { re-primed with UV-B and subjected to PEG stress }\end{array}$ \\
\hline
\end{tabular}

Estimation of ROS and lipid peroxidation: Hydrogen peroxide generation $\left(\mathrm{H}_{2} \mathrm{O}_{2}\right)$ was determined using the method of Junglee et al. (2014). Sample tissue was weighed and extracted in $5 \mathrm{~mL}$ of $0.1 \%$ ice-cold TCA. For $15 \mathrm{~min}$, the homogenate was centrifuged at 12,000 rpm. The supernatant was collected and used to estimate the amount of hydrogen peroxide. The supernatant of $0.5 \mathrm{~mL}$ was mixed with $0.5 \mathrm{~mL}$ of potassium phosphate buffer ( $\mathrm{pH} 7)$, to which $1 \mathrm{~mL}$ of $1 \mathrm{M}$ potassium iodide was added. The color intensity of the mixture was measured at $390 \mathrm{~nm}$ using UV-VIS spectrophotometer (Systronics 2201, Gujarat, India). The standard used was hydrogen peroxide. Superoxide content $\left(\mathrm{O}_{2}{ }^{-}\right)$was analyzed based 
on the procedure of Doke (1983). The tissue was cut into small pieces $(1 \times 1 \mathrm{~mm})$ and pooled in a $0.01 \mathrm{M}$ potassium phosphate buffer ( $\mathrm{pH} 7.8$ ) containing NBT at $0.05 \%$ and $10 \mathrm{mM} \mathrm{NaN}_{3}$. The mixture was kept in a water bath $\left(85^{\circ} \mathrm{C}\right)$ for $15 \mathrm{~min}$. After incubation, the mixture was quickly transferred to an ice bath to reduce the temperature. The absorbance of the mixture was measured at $580 \mathrm{~nm}$ after cooling.

The malondialdehyde content (MDA) was estimated using a method of Heath and Packer (1968). The tissue of $500 \mathrm{mg}$ was weighed and homogenized in $5 \mathrm{~mL}$ of $5 \%$ trichloroacetic acid. At room temperature, the mixture was centrifuged at $12,000 \mathrm{rpm}$ for $15 \mathrm{~min}$. The supernatant was collected in a clean test tube and used to estimate MDA content. Two milliliters of supernatant were mixed with an equal amount of $0.5 \%$ thiobarbituric acid (TBA) in $20 \%$ trichloroacetic acid (TCA). The solution was heated to $95^{\circ} \mathrm{C}$ for $24 \mathrm{~min}$, cooled, and then centrifuged for $2 \mathrm{~min}$ at $3,000 \mathrm{rpm}$. UV-VIS spectrophotometer (Systronics 2201, Gujarat, India) was used to measure the OD of solution at 532 and $600 \mathrm{~nm}$ in comparison to a reagent blank.

Estimation of mitochondrial activity: Mitochondria isolation was performed based on the procedure of Kollöffel (1967). The oxygen consumption of mitochondria was measured at $25^{\circ} \mathrm{C}$ using a Clark-type $\mathrm{O}_{2}$ electrode according to Schmitt and Dizengremel (1989). The rate of succinate oxidation was calculated in terms of nmol of $\mathrm{O}_{2}$ consumed $\mathrm{mg}^{-1}$ (protein) $\mathrm{min}^{-1}$. The protein content of the mitochondrial preparations was determined using the Bradford (1976) method.

Chlorophyll (Chl) $\boldsymbol{a}$ fluorescence parameters: Different Chl fluorescence parameters, such as maximal fluorescence $\left(\mathrm{F}_{\mathrm{m}}\right)$, an indicator of inhibition of electron donation by oxygen-evolving complex $(\mathrm{OEC})\left(\mathrm{F}_{\mathrm{K}} / \mathrm{F}_{\mathrm{J}}\right)$, relative variable fluorescence at $\mathrm{J}$ step $\left(\mathrm{V}_{\mathrm{J}}\right)$, electron transport quantum yield $\left(\Phi \mathrm{E}_{0}\right)$, performance index $\left[\mathrm{PI}_{(\mathrm{abs})}\right]$, were measured using Plant Efficiency Analyzer (Handy PEA, Hansatech Ltd., Norfolk, UK) (Strasser et al. 2004). All measurements were taken on the upper surface of the fully expanded leaves after a 20-min dark-adaptation period, with the help of light exclusion clips attached to the leaf surface before the measurements. Maximal fluorescence was induced by a 1 -s pulse of white light $\left[3,000 \mu \mathrm{mol}\left(\right.\right.$ photon) $\left.\mathrm{m}^{-2} \mathrm{~s}^{-1}\right]$ with the gain adjusted to 0.7 to avoid scaling problems. Data were analyzed with radar plot using Biolyzer HP3 software (Chl $a$ fluorescence analyzing program developed by Bioenergetics Laboratory, University of Geneva, Switzerland).

Photosynthetic gas-exchange parameters: Leaf gasexchange parameters were analyzed by using a LI-6400 portable photosynthesis system (infra-red gas analyzer, LI-COR, Lincoln, Nebraska, USA). The various leaf gasexchange parameters, such as net photosynthetic rate $\left(P_{\mathrm{N}}\right)$, stomatal conductance $\left(g_{\mathrm{s}}\right)$, intercellular $\mathrm{CO}_{2}$ concentration $\left(C_{\mathrm{i}}\right)$, and transpiration rate $(E)$, were measured in rice seedlings. Reading was recorded between 9:00-10:00 h at growth temperature and ambient $\mathrm{CO}_{2}$ conditions. The internal light source in $L I-6400$ was set at an intensity of $1,500 \mu \mathrm{mol}$ (photon) $\mathrm{m}^{-2} \mathrm{~s}^{-1}$ to ensure a constant and uniform light across all measurements.

Assay of enzymatic and nonenzymatic antioxidants: The preparation of enzyme extracts from samples was carried out based on the protocol of Yin et al. (2009). The protein content of the enzyme extract was assessed using the Bradford (1976) method, with defatted bovine serum albumin (fraction V) as the standard. Catalase (CAT, EC 1.11.1.6) activity was determined by measuring the decrease in absorbance at $240 \mathrm{~nm}$ for $1 \mathrm{~min}$ following the decomposition of $\mathrm{H}_{2} \mathrm{O}_{2}$ ( $\mathrm{Kar}$ and Mishra 1976). One unit of the enzyme activity was defined as micromoles of $\mathrm{H}_{2} \mathrm{O}_{2}$ decomposed per min per mg protein. The ability of superoxide dismutase (SOD, EC 1.15.1.1) to inhibit the photochemical reduction of nitroblue tetrazolium (NBT) was determined using the method of Giannopolitis and Ries (1977). One unit of SOD activity was defined as the enzyme required to inhibit the photochemical reduction of NBT by $50 \%$. Ascorbate peroxidase (APX, EC 1.11.1.11) activity was analyzed according to Nakano and Asada (1981). One unit of the enzyme activity was defined as micromoles of ascorbate oxidized per mg of protein.

The ascorbate and glutathione content in fresh samples were measured using the method of Chen and Wang (2002) with L-ascorbic acid and reduced glutathione serving as respective standards. The plant material was weighed and homogenized with $5 \mathrm{~mL}$ of $5 \%$ TCA. The homogenate was filtered and centrifuged at $12,000 \mathrm{rpm}$ for $15 \mathrm{~min}$ at $4^{\circ} \mathrm{C}$. For estimation of reduced ascorbate content, an aliquot of $0.1 \mathrm{~mL}$ of the supernatant was mixed well with $0.3 \mathrm{~mL}$ of $200 \mathrm{mM} \mathrm{NaH} \mathrm{PO}_{4}$. To this mixture, $0.5 \mathrm{~mL}$ of $10 \%(\mathrm{v} / \mathrm{v}) \mathrm{TCA}, 0.4 \mathrm{~mL}$ of $42 \%(\mathrm{v} / \mathrm{v}) \mathrm{H}_{3} \mathrm{PO}_{4}$, $0.4 \mathrm{~mL}$ of $4 \%(\mathrm{w} / \mathrm{v})$ bipyridyl (dissolved in $70 \%$ alcohol), and $0.2 \mathrm{~mL}$ of $3 \% \mathrm{FeCl}_{3}(\mathrm{w} / \mathrm{v})$ was added. The mixture was incubated at $42^{\circ} \mathrm{C}$ for $15 \mathrm{~min}$ and the absorbance was measured immediately after incubation at $524 \mathrm{~nm}$ using UV-VIS spectrophotometer (Systronics 2201, Gujarat, India). The ascorbate content was expressed on dry mass.

For estimation of reduced glutathione content, to an aliquot of $0.5 \mathrm{~mL}$ of the supernatant, $2.6 \mathrm{~mL}$ of $150 \mathrm{mM}$

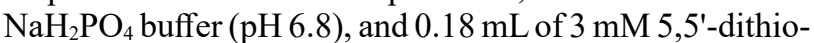
bis(2-nitrobenzoic acid, DTNB) were added (DTNB was dissolved in $100 \mathrm{mM}$ phosphate buffer, $\mathrm{pH}$ 6.8) and kept for $5 \mathrm{~min}$. Then, the absorbance was read at $412 \mathrm{~nm}$ using UV-VIS spectrophotometer (Systronics 2201, Gujarat, India). The glutathione content was expressed on dry mass.

Proline content was estimated according to the protocol of Bates et al. (1973) and L-proline was used as the standard. For the estimation of proline, fresh tissue of $500 \mathrm{mg}$ was homogenized in $5 \mathrm{~mL}$ of $3 \%$ sulfosalicylic acid (w/v) solution and centrifuged for $10 \mathrm{~min}$ at 10,000 $\mathrm{rpm}$ at $4^{\circ} \mathrm{C}$ and the supernatant was collected. One milliliter of supernatant was taken into test tubes in 
triplicate and an equal volume of ice-cold acetic acid and $2.5 \%$ acid ninhydrin were added to it. After that, the tubes were placed in a boiling water bath for $1 \mathrm{~h}$. To the reaction mixture, $4 \mathrm{~mL}$ of toluene were added, and vigorously stirred for 20-30 s using a vortex mixer. The chromophoretoluene layer was separated with care, and the optical density of the chromophoric layer was measured using a UV-VIS spectrophotometer (Systronics 2201, Gujarat, India) at $520 \mathrm{~nm}$. The proline content was expressed on dry mass.

The content of anthocyanins was determined using the method of Mancinelli et al. (1975), with minor modifications. Samples of fresh rice leaves were homogenized and extracted in $5 \mathrm{~mL}$ of methanol (methanol: $\mathrm{HCl}$, 99:1) using a mortar and pestle. The extract was stored at $4^{\circ} \mathrm{C}$ for $24 \mathrm{~h}$ and the volume was made up to $5 \mathrm{~mL}$. The concentration of anthocyanins was determined using a UV-VIS spectrophotometer (Systronics 2201, Gujarat, India). The absorbance at $530 \mathrm{~nm}$ was recorded. According to the method of Mirecki and Teramura (1984), flavonoids were extracted and estimated. After homogenizing tissue samples using $5 \mathrm{~mL}$ of $\mathrm{HCl}$ :methanol: $\mathrm{H}_{2} \mathrm{O}(1: 79: 20)$ the homogenate was kept at room temperature for $24 \mathrm{~h}$, flavonoids were extracted. The absorbance at $315 \mathrm{~nm}$ was recorded. The content of anthocyanins and flavonoids was expressed on dry mass.

Gene expression study of enzymatic antioxidants and stress-related proteins: Gene-specific primers of $\mathrm{Cu} / \mathrm{Zn}$ $S O D$, Cat A, APx 1, Hsp 90, group $3 L E A$, and actin (internal control) were designed using the Primer-3 software (Table 1S, supplement). Total RNA was extracted from the primed and non-primed seedlings of Vaisakh plants grown in PEG according to the protocol of ValenzuelaAvendaño et al. (2005) and the concentration of RNA was estimated using Genova Nanodrop (Jenway, Cole-Parmer $L t d .$, UK). One $\mu \mathrm{g}$ of RNA was used for the first-strand cDNA synthesis using the iScript cDNA Synthesis Kit (Bio-Rad Laboratories Inc., USA). One $\mu 1$ of cDNA with Taq DNA Polymerase $2 \times$ Master Mix RED (Amplicon) and gene-specific primers according to the manufacturer's instruction were used for PCR (Bio-Rad C1000). The RT-PCR products were electrophoresed and visualized on a $1 \%$ agarose gel. The band intensities of PCR products were analyzed by using Image $J$ software. The signal intensity value of each sample and for a specific gene was divided by that of the value obtained for actin gene for the same sample and the resulting ratios of at least three gels were plotted for each sample.

Statistical analysis: Statistical study of different parameters was carried out using Tukey's test at 5\% probability level. One-way analysis of variance (ANOVA) was performed using the SPSS software 16.0 (SPSS Inc., Chicago, USA). The data represent mean \pm standard error and the values are an average of recordings from three independent experiments, each with three replicates (i.e., $n=9)$.

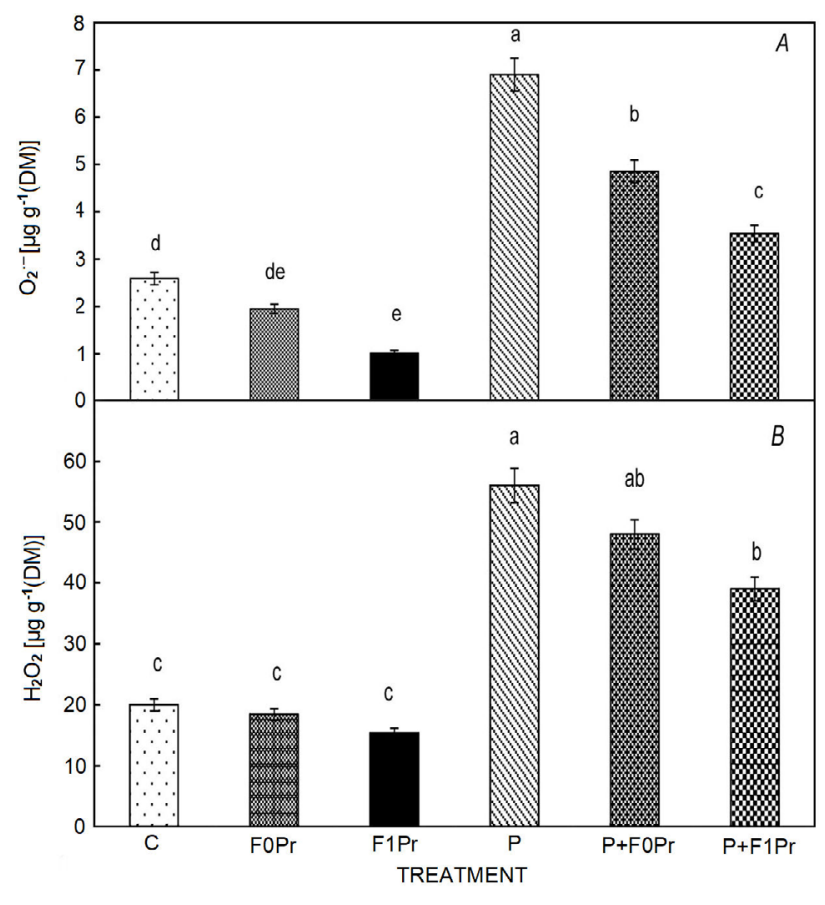

Fig. 1. Superoxide $(A)$ and hydrogen peroxide $(B)$ content in rice seedlings exposed to PEG stress on $9 \mathrm{~d}$. C (control), $\mathrm{F}_{0} \mathrm{Pr}$ (seeds collected from the UV-B-primed plants grown without any stress), $F_{1} \operatorname{Pr}$ (seeds collected from the UV-B-primed plants re-primed with UV-B and grown without any stress), P (seeds subjected to PEG stress), $\mathrm{P}+\mathrm{F}_{0} \mathrm{Pr}$ (seeds collected from the UV-B primed plants subjected to $\mathrm{PEG}$ stress), $\mathrm{P}+\mathrm{F}_{1} \operatorname{Pr}$ (seeds collected from the UV-B-primed plants re-primed with UV-B and subjected to PEG stress).

\section{Results}

ROS accumulation and membrane damage: The $\mathrm{H}_{2} \mathrm{O}_{2}$ and $\mathrm{O}_{2}{ }^{-}$generation was significantly enhanced in rice seedlings under PEG stress and it was 180 and $166 \%$ more compared to the control. However, a significant reduction in the content of $\mathrm{H}_{2} \mathrm{O}_{2}$ was observed in seedlings that emerged from UV-B-primed seeds. The major reduction was associated with the seedlings that emerged from UV-B-re-primed seeds followed by seedlings that emerged from the primed seeds. Similarly, the rate of $\mathrm{O}_{2}{ }^{-}$generation decreased following UV-B-seed priming up to $37 \%$ in $\mathrm{P}+\mathrm{F}_{1} \mathrm{Pr}$ and $87 \%$ in $\mathrm{P}+\mathrm{F}_{0} \mathrm{Pr}$ as compared to the control (Fig. 1).

The rate of lipid peroxidation (MDA content) increased in response to PEG stress $(87 \%)$ in rice seedlings. However, seedlings that emerged from UV-B-primed seeds showed a significantly reduced rate of lipid peroxidation as compared to the control. The most prominent reduction was found in $\mathrm{P}+\mathrm{F}_{1} \operatorname{Pr}(21 \%)$ followed by $\mathrm{P}+\mathrm{F}_{0} \operatorname{Pr}(50 \%)$ compared with the control (Fig. 2A).

Effect on mitochondrial activity: Mitochondrial activity in the rice seedlings decreased by $36 \%$ under PEG 


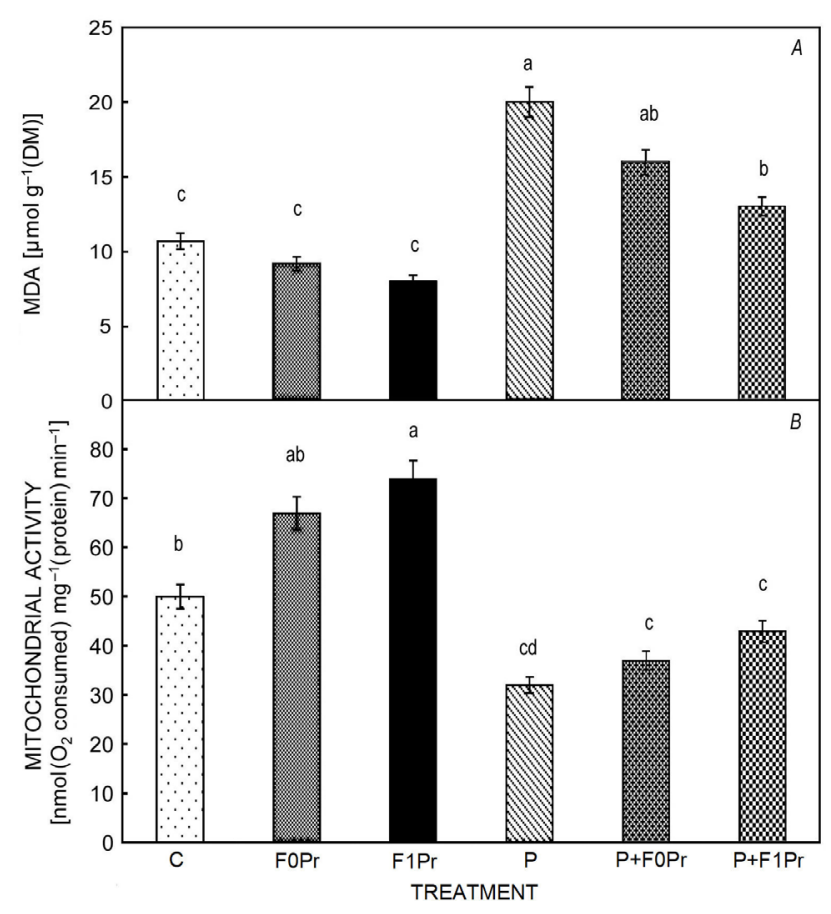

Fig. 2. Malondialdehyde (MDA) content $(A)$ and mitochondrial activity $(B)$ in rice seedlings exposed to PEG stress on $9 \mathrm{~d}$. $\mathrm{C}$ (control), $\mathrm{F}_{0} \mathrm{Pr}$ (seeds collected from the UV-B-primed plants grown without any stress), $F_{1} \operatorname{Pr}$ (seeds collected from the UV-B primed plants re-primed with UV-B and grown without any stress), $\mathrm{P}$ (seeds subjected to $\mathrm{PEG}$ stress), $\mathrm{P}+\mathrm{F}_{0} \operatorname{Pr}$ (seeds collected from the UV-B-primed plants subjected to $\mathrm{PEG}$ stress), $\mathrm{P}+\mathrm{F}_{1} \mathrm{Pr}$ (seeds collected from the UV-B-primed plants re-primed with UV-B and subjected to PEG stress).

stress. However, seed priming maintained mitochondrial activity in $\mathrm{P}+\mathrm{F}_{1} \operatorname{Pr}(48 \%)$ followed by $\mathrm{P}+\mathrm{F}_{0} \mathrm{Pr}(34 \%)$ seedlings on exposure to PEG stress as compared to the control. Maximum mitochondrial activity was observed in UV-B-primed rice seedlings, not exposed to PEG stress and it was higher in $\mathrm{P}+\mathrm{F}_{1} \operatorname{Pr}(69 \%)$ followed by $\mathrm{P}+\mathrm{F}_{0} \mathrm{Pr}$ (56\%) (Fig. 2B).

Chl $\boldsymbol{a}$ fluorescence parameters: The present study showed that the indicator of inhibition of electron donation by $\mathrm{OEC}\left(\mathrm{F}_{\mathrm{K}} / \mathrm{F}_{\mathrm{J}}\right)$ increased under PEG stress. $F_{K} / F_{J}$ significantly decreased in seedlings that emerged from UV-B-primed seeds when compared to the nonprimed ones. Improvement of donor side intactness due to UV-B seed priming was observed in the order $\mathrm{F}_{1} \mathrm{Pr}>$ $\mathrm{F}_{0} \mathrm{Pr}>\mathrm{C}>\mathrm{P}+\mathrm{F}_{1} \mathrm{Pr}>\mathrm{P}+\mathrm{F}_{0} \mathrm{Pr}+\mathrm{P}>\mathrm{P}$. Reduction in $\mathrm{PI}_{(\mathrm{abs})}$ was observed in rice seedlings exposed to PEG stress. However, the rate of $\mathrm{PI}_{(\mathrm{abs})}$ increased in seedlings that emerged from UV-B-primed seeds: $\mathrm{F}_{1} \operatorname{Pr}(70 \%)$ followed by $\mathrm{F}_{0} \operatorname{Pr}(23 \%)$. The increase in $\mathrm{PI}_{(\mathrm{abs})}$ as a result of UV-B seed priming was higher in seedlings that emerged from $\mathrm{F}_{1} \mathrm{Pr}$ followed by $\mathrm{F}_{0} \mathrm{Pr}$.

In the case of maximal fluorescence $\left(F_{m}\right)$, there was a significant difference between $F_{m}$ of PSII in UV-Bprimed and non-primed seedlings. $F_{m}$ of PSII decreased under PEG stress, a higher reduction in $\mathrm{F}_{\mathrm{m}}$ was recorded in the non-primed rice seedlings exposed to PEG stress $(59 \%)$. The increase in $\mathrm{F}_{\mathrm{m}}$ recorded in seedlings raised from UV-B seed priming was higher in $F_{1}$ followed by $F_{0}$ generation as compared to control. A significant reduction in electron transport quantum yield $\left(\Phi \mathrm{E}_{0}\right)$ was observed in rice seedlings under PEG stress $(33 \%)$. Higher $\Phi \mathrm{E}_{0}$ was recorded in seedlings that emerged from UV-B-primed seeds and it was the highest in $\mathrm{F}_{1} \mathrm{Pr}$ followed by $\mathrm{F}_{0} \mathrm{Pr}$. The present study also shows that a significant increase in relative variable fluorescence at the $\mathrm{J}$ step $\left(\mathrm{V}_{\mathrm{J}}\right)$ was associated with non-primed rice seedlings under PEG stress $(38 \%)$. However, UV-B seed priming effectively reduced the relative variable fluorescence at the $J$ step $\left(V_{J}\right)$. The decrease in $\mathrm{J}\left(\mathrm{V}_{\mathrm{J}}\right)$ in rice seedlings due to UV-B seed priming was higher in $\mathrm{F}_{1} \mathrm{Pr}$ followed by $\mathrm{F}_{0} \mathrm{Pr}$ compared with the control (Fig. 3).

Photosynthetic gas-exchange parameters: The foliar gas-exchange parameters, such as net photosynthetic rate $\left(P_{\mathrm{N}}\right)$, stomatal conductance $\left(g_{\mathrm{s}}\right)$, intercellular $\mathrm{CO}_{2}$ concentration $\left(C_{\mathrm{i}}\right)$, and transpiration rate $(E)$ were significantly reduced in rice seedlings on exposure to PEG stress. A greater reduction of $P_{\mathrm{N}}(58 \%), g_{\mathrm{s}}(57 \%), C_{\mathrm{i}}(22 \%)$, and $E(43 \%)$ was observed in non-primed rice seedlings under PEG stress. However, UV-B priming improved all these parameters in rice seedlings exposed to PEG stress. A prominent increase was observed in $\mathrm{P}+\mathrm{F}_{1} \mathrm{Pr}$ seedlings

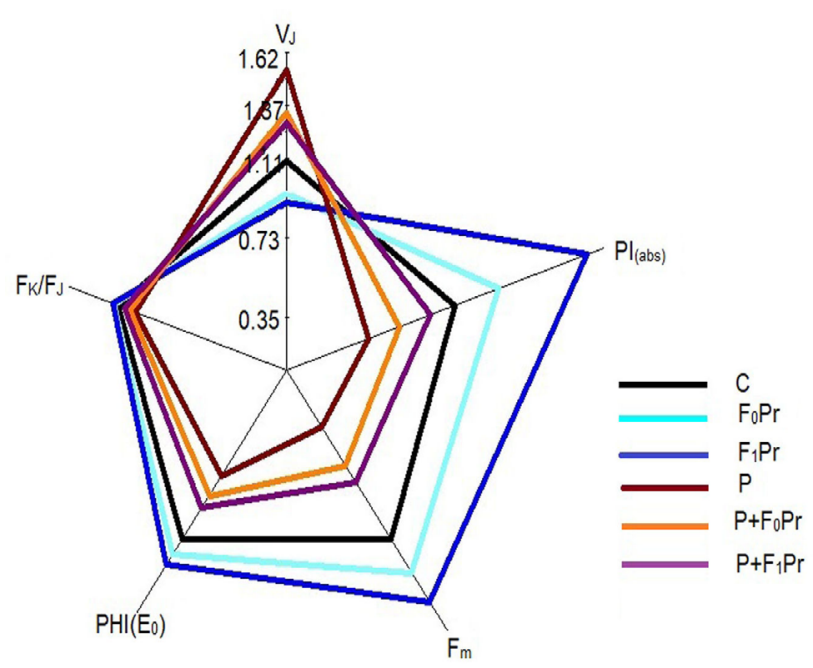

Fig. 3. Radar plot of selected Chl $a$ fluorescence parameters characterizing PSII of rice seedlings exposed to PEG stress on 9 d. C (control), $\mathrm{F}_{0} \mathrm{Pr}$ (seeds collected from the UV-B-primed plants grown without any stress), $F_{1} \operatorname{Pr}$ (seeds collected from the UV-B-primed plants re-primed with UV-B and grown without any stress), $\mathrm{P}$ (seeds subjected to $\mathrm{PEG}$ stress), $\mathrm{P}+\mathrm{F}_{0} \mathrm{Pr}$ (seeds collected from the UV-B-primed plants subjected to PEG stress), $\mathrm{P}+\mathrm{F}_{1} \operatorname{Pr}$ (seeds collected from the UV-B-primed plants re-primed with UV-B and subjected to PEG stress). $F_{K} / F_{J}$ - indicator of inhibition of electron donation by oxygen-evolving complex; $\mathrm{F}_{\mathrm{m}}$ - maximal fluorescence; $\mathrm{PI}_{(\mathrm{abs})}-$ performance index; $\mathrm{V}_{\mathrm{J}}$ relative variable fluorescence at $\mathrm{J}$ step; $\Phi \mathrm{E}_{0}$ - electron transport quantum yield. 
followed by $\mathrm{P}+\mathrm{F}_{0} \mathrm{Pr}$ seedlings not exposed to PEG stress as compared to the control (Fig. 4).

Nonenzymatic antioxidants: Nonenzymatic antioxidants, such as ascorbate, glutathione, anthocyanin, and flavonoids increased in rice seedlings of Vaisakh under PEG stress. Higher content of glutathione (GSH) was noted in $\mathrm{F}_{1} \mathrm{Pr}$ $(365 \%)$ followed by $\mathrm{F}_{0} \operatorname{Pr}(267 \%)$ priming under $\mathrm{PEG}$ stress. UV-B priming and re-priming followed by the exposure to PEG stress resulted in enhanced contents of ascorbate in seedlings by 186 and $275 \%$, respectively. Likewise, anthocyanin and flavonoids increased on exposure to PEG stress in Vaisakh (90 and 125\%, respectively). UV-B priming and re-priming resulted in further enhancement of anthocyanin content by 109 and $137 \%$ and flavonoids by 150 and $183 \%$, respectively, in Vaisakh under PEG stress (Fig. 1S, supplement).

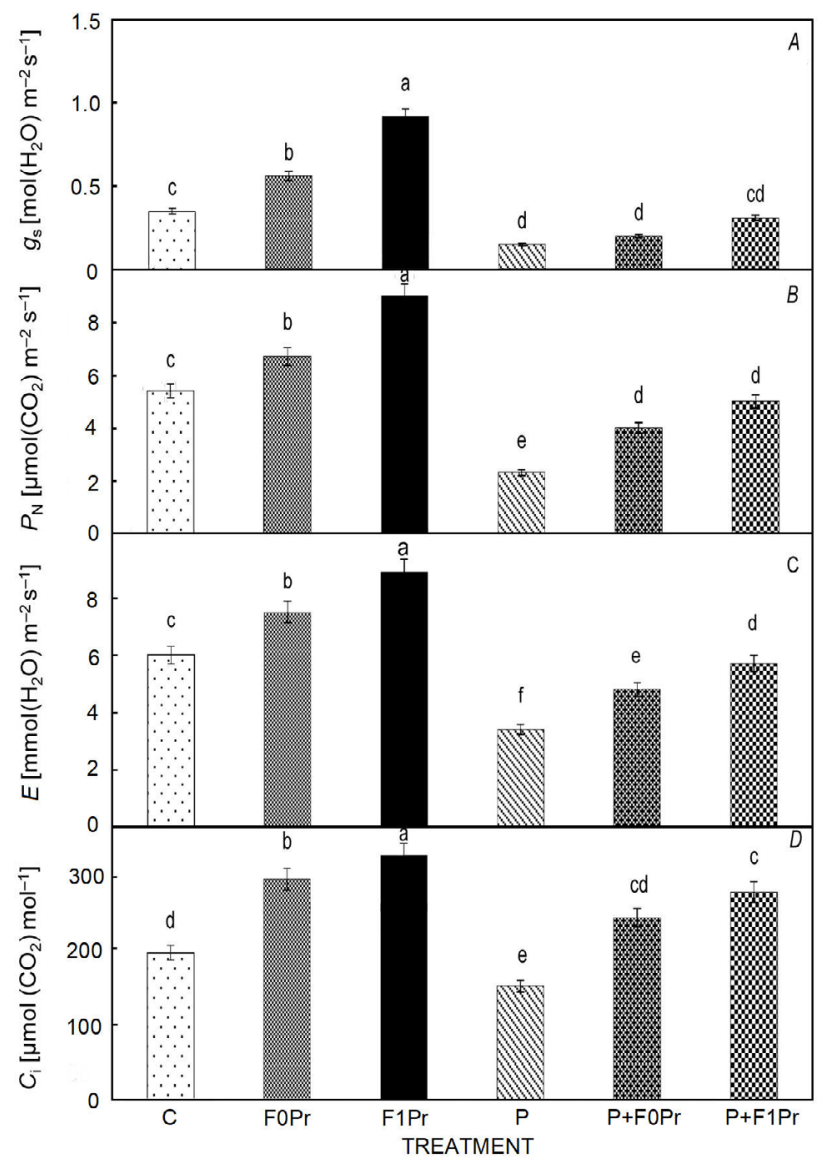

Fig. 4. Foliar gas-exchange parameters in rice seedlings exposed to PEG stress on $9 \mathrm{~d}$. C (control), $\mathrm{F}_{0} \operatorname{Pr}$ (seeds collected from the UV-B-primed plants grown without any stress), $\mathrm{F}_{1} \operatorname{Pr}$ (seeds collected from the UV-B-primed plants re-primed with UV-B and grown without any stress), $\mathrm{P}$ (seeds subjected to PEG stress), $\mathrm{P}+\mathrm{F}_{0} \mathrm{Pr}$ (seeds collected from the UV-B primed plants subjected to PEG stress), $\mathrm{P}+\mathrm{F}_{1} \mathrm{Pr}$ (seeds collected from the UV-B-primed plants re-primed with UV-B and subjected to PEG stress). $C_{\mathrm{i}}-$ intercellular $\mathrm{CO}_{2}$ concentration; $E$ - transpiration rate; $g_{\mathrm{s}}-$ stomatal conductance; $P_{\mathrm{N}}-$ net photosynthetic rate.
Antioxidant enzymes: In response to PEG stress, SOD activity increased by $170 \%$ in Vaisakh. The same trend was observed in the case of catalase (201\%) and ascorbate peroxidase $(233 \%)$ as compared to the control. SOD (270\%), catalase $(273 \%)$, and APX (308\%) activities prominently increased in $\mathrm{F}_{1} \mathrm{Pr}$ seedlings under PEG stress. Similarly, $\mathrm{F}_{0} \mathrm{Pr}$ increased SOD (220\%), catalase (238\%), and APX (288\%) activities under PEG stress (Fig. 2S, supplement).

Gene expression: All the tested genes that regulate antioxidative enzymes and stress proteins showed increased expression in response to UV-B priming. The expression

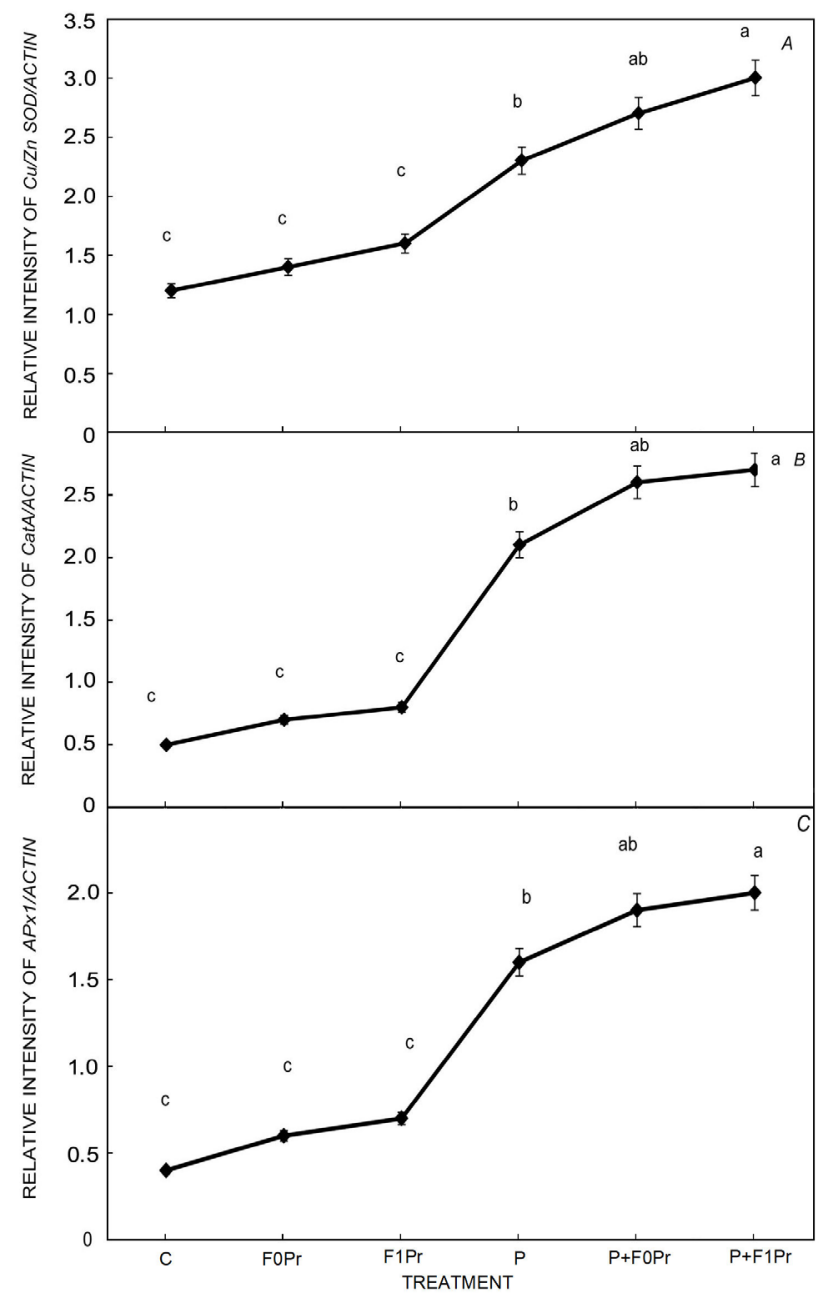

Fig. 5. Expression analysis of superoxide dismutase $(\mathrm{Cu} / \mathrm{Zn}$ $S O D)(A)$, catalase $(C a t A)(B)$, and ascorbate peroxidase $(A P x l)$ $(C)$ in rice seedlings exposed to PEG stress on $9 \mathrm{~d}$. C (control), $\mathrm{F}_{0} \mathrm{Pr}$ (seeds collected from the UV-B-primed plants grown without any stress), $F_{1} \operatorname{Pr}$ (seeds collected from the UV-B-primed plants re-primed with UV-B and grown without any stress), $\mathrm{P}$ (seeds subjected to $\mathrm{PEG}$ stress), $\mathrm{P}+\mathrm{F}_{0} \operatorname{Pr}$ (seeds collected from the UV-B-primed plants subjected to PEG stress), $\mathrm{P}+\mathrm{F}_{1} \mathrm{Pr}$ (seeds collected from the UV-B-primed plants re-primed with UV-B and subjected to PEG stress). 
analysis of three genes related to antioxidant enzymes was conducted by using specific primers. These genes include $\mathrm{Cu} / \mathrm{Zn} \mathrm{SOD}$ (encoding superoxide dismutase), Cat $A$ (catalase), and $A P x 1$ (ascorbate peroxidase). In response to UV-B seed priming, the expression of $\mathrm{Cu} / \mathrm{Zn}$ $S O D, C a t A$, and APxl of rice seedlings was upregulated as compared to corresponding control on exposure to PEG stress and the increasing order of gene expression was $\mathrm{P}+\mathrm{F}_{1} \mathrm{Pr}>\mathrm{P}+\mathrm{F}_{0} \mathrm{Pr}>\mathrm{P}>\mathrm{F}_{1} \operatorname{Pr}>\mathrm{F}_{0} \mathrm{Pr}>\mathrm{C}$ (Fig. 5).

The present study proved that gene expression at mRNA transcript level of stress-related proteins such as group $3 L E A$ and $H s p 90$ was significantly enhanced in rice as a result of UV-B priming in PEG-stress conditions. A significant increase in the gene expression level of Hsp90 was observed in seedlings that emerged from UV-B-primed seeds exposed to PEG stress. Similarly, an increase in gene expression of $H s p 90$ was noticed in seedlings subjected to PEG stress. A significant increase in gene expression of LEA proteins was observed in seedlings

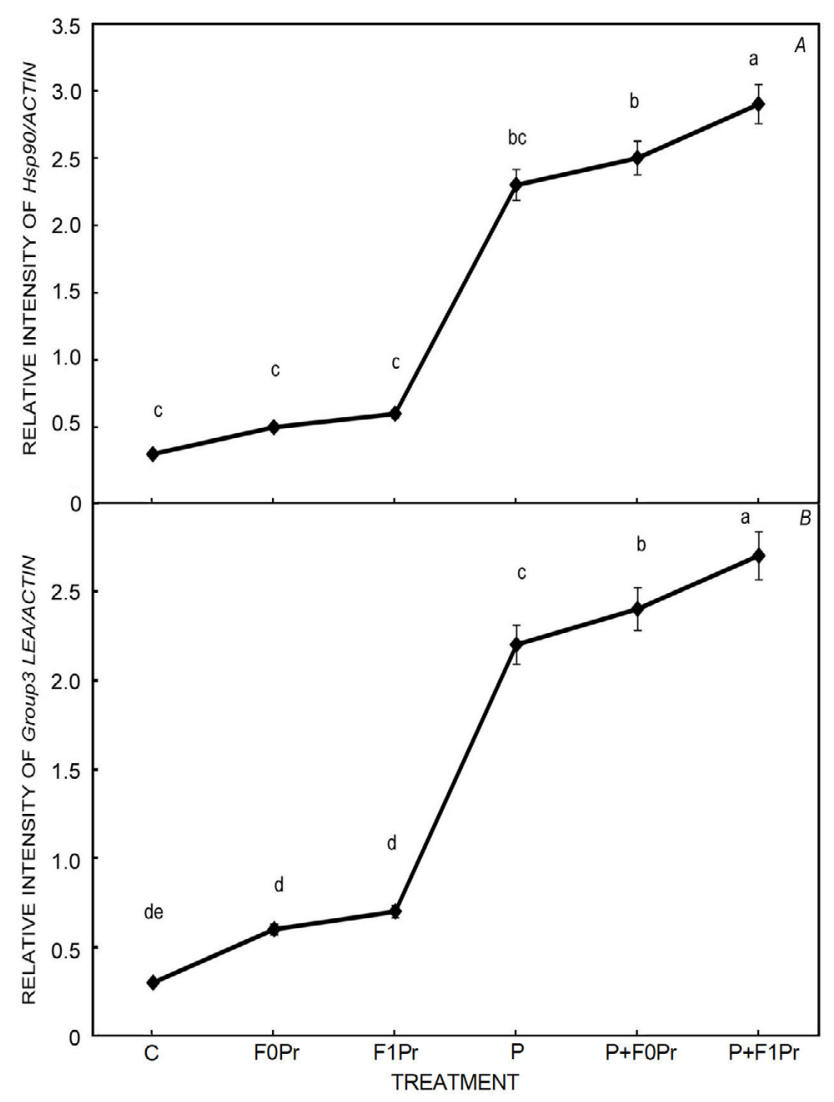

Fig. 6. Expression analysis of $H s p 90(A)$ and $L E A(B)$ in rice seedlings exposed to PEG stress on $9 \mathrm{~d}$. C (control), $\mathrm{F}_{0} \operatorname{Pr}$ (seeds collected from the UV-B-primed plants grown without any stress), $\mathrm{F}_{1} \operatorname{Pr}$ (seeds collected from the UV-B-primed plants re-primed with UV-B and grown without any stress), $\mathrm{P}$ (seeds subjected to $\mathrm{PEG}$ stress), $\mathrm{P}+\mathrm{F}_{0} \mathrm{Pr}$ (seeds collected from the UV-B primed plants subjected to $\mathrm{PEG}$ stress), $\mathrm{P}+\mathrm{F}_{1} \operatorname{Pr}$ (seeds collected from the UV-B-primed plants re-primed with UV-B and subjected to PEG stress). exposed to PEG stress as a response to both types of UV-B priming. The highest gene expression was observed in the order $\mathrm{P}+\mathrm{F}_{1} \mathrm{Pr}>\mathrm{P}+\mathrm{F}_{0} \mathrm{Pr}>\mathrm{P}>\mathrm{F}_{1} \mathrm{Pr}>\mathrm{F}_{0} \mathrm{Pr}>\mathrm{C}$ (Fig. 6).

\section{Discussion}

The present study was conducted to examine the transgenerational effect of UV-B priming $\left(4 \mathrm{~kJ} \mathrm{~m}^{-2}\right)$ on seedlings of a stress-tolerant rice variety (Vaisakh) subjected to PEG stress. Our earlier studies have proved that seed priming with $4 \mathrm{~kJ} \mathrm{~m}^{-2}$ was effective in enhancing the innate stress tolerance of rice seedlings subjected to PEG stress (PEG 6,000) (Sen et al. 2021). A PEG 6,000 treatment mimics drought stress and results in lowering of plant's water potential due to osmotic stress (Ahmad et al. 2020). In response to abiotic stress, plants accumulate $\mathrm{ROS}$ resulting in oxidative damage (Pandey and Gautam 2020). Increased contents of $\mathrm{H}_{2} \mathrm{O}_{2}$ and $\mathrm{O}_{2}{ }^{-}$were observed in the rice seedlings that emerged from nonprimed seeds subjected to PEG stress. High ROS contents damage cell membranes, proteins, causing denaturation of proteins in the plant cells (Hasanuzzaman et al. 2020). PEG stress induces $\mathrm{H}_{2} \mathrm{O}_{2}$ and $\mathrm{O}_{2}{ }^{--}$generation, which, in turn, causes damage to membranes and thus disturbs cell membrane functioning. The control of membrane integrity and membrane-associated functions is crucial for stress tolerance (Rawat et al. 2021). Our results revealed that rice seedlings that emerged from UV-B-primed seeds (priming done at $\mathrm{F}_{0}$ and $\mathrm{F}_{1}$ generations) exposed to $\mathrm{PEG}$ stress maintain low ROS contents leading to a decrease in lipid peroxidation (Figs. 1, 2). The transgenerational priming memory retained in the seeds gets transferred to the offspring: the F1 generation, even in the absence of re-priming. Moreover, re-priming of seeds with UV-B in the $F_{1}$ generation further boosted this memory. Thus UV-B priming and re-priming resulted in the enhanced tolerance of rice seedlings through balanced redox homeostasis, with re-priming at $F_{1}$ generation being more effective.

Chloroplasts are the major ROS production sites of plant cells and have been reported to be the most sensitive organelles to abiotic stresses (Semwal and Khanna-Chopra 2018). By this finding, our results show that hampered photosynthetic activities of non-primed seedlings under PEG stress occurred due to imbalances in the antioxidant defense mechanism. Besides photosynthetic inhibition, PEG stress-induced ROS can destroy mitochondria membranes and proteins in seedlings. Increased ROS content by decreased mitochondrial and photosynthetic activities results in cell damage which makes the plant more susceptible to exposure to PEG stress (Sen et al. 2021). However, both types of UV-B priming resulted in enhanced functioning of antioxidant machinery because of the retention of priming memory, in turn leading to the maintenance of steady-state intracellular ROS concentrations, ensuring increased photosynthetic efficacy and mitochondrial activity in primed seedlings even under PEG stress.

Chl $a$ fluorescence can be used as a probe to examine and compare the tolerance potential of plants against stress 
(Tuba et al. 2010, Rapacz et al. 2015). Analysis of Chl a fluorescence parameters reveals that the efficiency of the water-splitting complex (increased $\mathrm{F}_{\mathrm{K}} / \mathrm{F}_{\mathrm{J}}$ ) was reduced in rice seedlings under PEG stress, leading to the inhibition of electron donation. A drastic drop in $\mathrm{F}_{\mathrm{v}} / \mathrm{F}_{0}$ was observed in the non-primed seedlings, due to the higher reduction of PSII activity. It was already reported that an increase in the $F_{K} / F_{J}$ ratio under stress is due to the inhibition of the electron donation by the OEC (Srivastava et al. 1995). The seedlings that emerged from the UV-B-primed seeds improved high PSII efficiency by the donor side intactness (constant $F_{K} / F_{J}$ ratio). The performance index, $\mathrm{PI}_{(\mathrm{abs})}$, is a quantitative representation of plant vitality, calculated from the density of the RC per chlorophyll, total electron transport, and relative expression of primary photochemistry (Strasser et al. 2004). PEG stress resulted in the reduction of $\mathrm{PI}_{(\mathrm{abs})}$ in rice seedlings, however, the reduction was lessened by both means of UV-B priming and re-priming. The reduction of $\mathrm{PI}_{(\mathrm{abs})}$ during drought exposure was due to the changes in antenna size, reduction in trapping efficiency, and reduction in electron transport from $\mathrm{Q}_{\mathrm{A}}$ (Strasser et al. 2004). Following this report, PEG-exposed non-primed seedlings showed a reduction in trapping of energy as well as electron transport (Fig. 3). The increment in the $\mathrm{PI}_{(\mathrm{abs})}$ of rice seedlings that emerged from both types of UV-B-primed seeds was due to improvement in photon trapping and electron transport. $\mathrm{V}_{\mathrm{J}}$ value increased in the non-primed stressed rice seedlings, but the increment was lesser in seedlings that emerged from UV-B primed and re-primed seeds. The increase in the relative variable fluorescence of PEGstressed rice seedlings may be due to the impairment of electron transfer from $\mathrm{Q}_{\mathrm{A}}$ to $\mathrm{Q}_{\mathrm{B}}$ in the photosynthetic electron transport chain. Similar to our findings, the report of Zhang et al. (2016) demonstrates that the $\mathrm{V}_{\mathrm{J}}$ value increased significantly under drought stress indicating that the decrease of PSII photosynthetic electron transport rate in tobacco leaves under drought stress mainly occurred at the PSII acceptor side. Previously, it was reported that the photochemical efficiency of the photosynthetic apparatus of plants may change in response to climate change (Dąbrowski et al. 2015).

Maximal fluorescence $\left(\mathrm{F}_{\mathrm{m}}\right)$ value was reduced in plants subjected to PEG stress and maximum reduction in $F_{m}$ value was recorded in the non-primed seedlings. Yamane et al. (2008) suggested a higher reduction in $F_{m}$ value in plants under stress was due to the degradation of $\mathrm{Chl}$ protein. PEG stress results in a decline of $F_{m}$ value and an increase in heat dissipation. Minimum $F_{m}$ reduction was noticed in both types of UV-B-primed seedlings and was due to the successful transfer of trapped energy to the photosynthetic electron transport chain, improving the photosynthetic rate. Electron transport quantum yield of PSII $\left(\Phi \mathrm{E}_{0}\right)$ denotes the effectiveness of photochemistry of PSII and energy transferred by photosynthetic pigments towards the photochemical reaction. $\Phi \mathrm{E}_{0}$ value declined in the non-primed PEG-stressed rice seedlings, but the decline was lesser in seedlings that emerged from seeds primed with UV-B in two different generations $\left(\mathrm{F}_{0}\right.$ and
$F_{1}$ ) seeds (Fig. 3). PEG stress reduces the photosynthetic rate possibly by reduced carbon dioxide assimilation due to the PEG-induced stomatal closure. It was reported that drought-induced stomatal closure reduced carbon dioxide assimilation and resulted in the reduction of $\Phi \mathrm{E}_{0}$ in potato plants (Boguszewska-Mańkowska et al. 2018). The present study proved that the PEG stress ultimately led to the reduction of photochemical yield of rice seedlings. However, transgenerational memory attained by UV-B priming resulted in the increased efficiency of the photochemistry of UV-B-primed seedlings.

The present study shows that PEG stress reduced the rate of foliar gas-exchange parameters, such as $P_{\mathrm{N}}, g_{\mathrm{s}}$, $C_{\mathrm{i}}$, and $E$ in rice seedlings (Fig. 4). Similar results were reported by Sheteiwy et al. (2018), wherein they reported that photosynthesis parameters, $P_{\mathrm{N}}, g_{\mathrm{s}}$, and $C_{\mathrm{i}}$, were reduced in rice under PEG-stress conditions. PEG stress decreased the rate of stomatal conductance which led to the reduction in intercellular $\mathrm{CO}_{2}$ and affected the photosynthetic rate. In accordance with the present study, Dąbrowski et al. (2017) indicated that stomatal conductance is reduced by salinity in ryegrass. The availability of $\mathrm{CO}_{2}$ in the chloroplast was strictly regulated by the stomatal closure under drought stress. The closure of stomata and the restriction of $\mathrm{CO}_{2}$ access result in lowering of electron transport process and as a result, overexcitation of the plant photosynthetic apparatus occurs. Thus, the system is more vulnerable to photodamage (Sheteiwy et al. 2018). Earlier stomatal closure could lead to limitation in $\mathrm{CO}_{2}$ diffusion, reduce the activity of photosynthetic enzymes, and ultimately decrease photochemical efficiency (Reddy et al. 2004). The priming and re-priming with UV-B alleviated stress effects through the enhancement in gas-exchange characteristics and $\mathrm{Chl} a$ fluorescence. A significant enhancement in stomatal conductance and the photosynthetic rate was reported in response to magneto priming in Glycine max (Fatima et al. 2021). Similar findings were also reported by Pogrzeba et al. (2017) in Miscanthus $\times$ giganteus cultivated on soil contaminated with trace elements under NPK fertilization and Kalaji and Nalborczyk (1991) in barley seedlings growing under salinity. The transgenerational priming memory retained in the seeds makes rice seedlings more tolerant to drought stress through improved detoxification mechanism and ensuring minimal interference of stress in the photosynthetic processes.

The reduction of photosynthetic rate in the present study in response to PEG stress might be caused by early stomatal closure, which could lead to limitation of the $\mathrm{CO}_{2}$ diffusion, reduce the activity of photosynthetic enzymes, and ultimately decrease photochemical efficiency of PSII (Pandey and Shukla 2015). The highly reduced $g_{\mathrm{s}}$ negatively impacted the $P_{\mathrm{N}}$ and $C_{\mathrm{i}}$ and both of these parameters are reduced as a result (Wang et al. 2016). Similarly, Nayyar and Gupta (2006) reported that methyl jasmonate application might cause stomatal closure which inhibited $\mathrm{CO}_{2}$ absorption and ultimately resulted in declined photosynthetic activity. However, the enhanced stomatal conductance that resulted from 
both modes of priming enhanced both the intercellular $\mathrm{CO}_{2}$ concentrations and photosynthetic rates of stressed seedlings (Fig. 4).

To combat drought-induced oxidative stress, plants have a variety of defense mechanisms, including enzymatic and nonenzymatic antioxidants. Increased activities of nonenzymatic antioxidants, such as ascorbate, glutathione, anthocyanin, and flavonoids, in response to priming and re-priming with UV-B imparted tolerance towards PEG-induced drought stress in Vaisakh. Nonenzymatic antioxidants protect cells by directly detoxifying ROS through donating electrons or hydrogen or reducing substrates for antioxidant enzymes (Gill and Tuteja 2010). The prominent effect of priming and re-priming effect of UV-B on the increased content of ascorbate and glutathione indicates the transgenerational priming efficiency of UV-B which resulted in enhanced tolerance of rice seedlings through an efficient antioxidation mechanism. Ascorbate acts as an alternative electron donor for PSII in leaves with inactive oxygen-evolving complex, and thereby protects PSII from donor side photoinhibition (Tóth et al. 2011). Glutathione, a low-molecular-mass thiol ( $\gamma$-glutamyl-cysteinyl glycine), functions as a reductant in the scavenging of ROS during stress. Glutathione along with ascorbate play a central role in the antioxidation mechanism (Heyneke et al. 2013). The transgenerational priming memory retained in the seeds gets transferred to the offspring without any loss. Moreover, UV-B re-priming in the $F_{1}$ generation further boosted the innate tolerance potential of a tolerant variety, achieved through priming in $\mathrm{F}_{0}$ generation, resulting in stable cellular redox homeostasis.

The UV-B priming and re-priming mediated increase in anthocyanin and flavonoid content of rice seedlings; it indicates that anthocyanin and flavonoid have a major role in the alleviation of ROS accumulation as a result of PEG stress (Fig. 1S). A study by Sytar et al. (2018) confirmed that the level of UV radiation played a dominant role in the accumulation of flavonoids and anthocyanins in lettuce plants grown in diverse environments. Flavonoids are secondary metabolites that are synthesized in the phenylpropanoid pathway and assist in combating ROS. Also, flavonoids play an important role in seed germination, drought, and temperature resistance (Hussain et al. 2019). Anthocyanins play a photoprotective and antioxidative role in plants; they accumulate in response to various environmental stresses which help the plant to survive (Zheng et al. 2021). Increased anthocyanin and flavonoid content in the UV-B primed and re-primed rice seedlings under PEG stress maintain redox homeostasis as a result of transgenerational level priming efficiency of $\mathrm{F}_{0}$-UV-B priming.

The activities of SOD, CAT, and APX were enhanced under PEG stress. However, UV-B priming and repriming with UV-B resulted in further amplification of SOD, CAT, and APX activities in rice seedlings. The amplification in the activity of these enzymes under $\mathrm{NaCl}$ and PEG stressors was already reported in rice varieties Neeraja and Vaisakh (Sen et al. 2021) Higher activity of these enzymes was more prominent after re-priming with
UV-B in the tolerant variety Vaisakh (Fig. 2S). Increased ROS-scavenging enzyme activities have been linked to stress-induced oxidative stress tolerance and this was accompanied by the change in expression of antioxidants and stress-related proteins. Seed priming augments stress tolerance by enhanced production and accumulation of stress proteins and antioxidants resulting in reduced ROS production under stress conditions (Chen and Arora 2013). The current study shows that UV-B priming retains priming memory in rice seedlings which triggers the antioxidation mechanism in seedlings of $F_{1}$ generation on exposure to PEG stress in the following generation. It was already reported that $C u / Z n S O D, A P x l$, and $C a t A$ have important roles in plant tolerance towards cold, oxidative, and drought stresses (Rossatto et al. 2017). UV-B priming enhanced expression of $C u / Z n S O D, A P x 1$, and $C a t A$ in seedlings on exposure to PEG stress (Fig. 5). Improved activity of antioxidant enzymes in response to UV-B priming of seeds was already reported in rice varieties (Sen et al. 2021). Gene expression of Cu/Zn SOD, Cat A, and $A P x 1$ was improved as a consequence of UV-B priming and re-priming while seedlings were exposed to PEG stress and such a situation would be more supportive for effective photosynthesis as discussed above. The increased gene expression rate of $\mathrm{Cu} / \mathrm{Zn} S O D$ and $A P X$ improved the photosynthetic performance in tobacco under photooxidative stress (Badawi et al. 2004a,b). Both types of UV-B seed priming regulate $C A T$ and $A P X$ expression to limit PEG stress-induced ROS generation and at the same time allow an optimal content of $\mathrm{H}_{2} \mathrm{O}_{2}$ for mediating its signaling functions.

The enhanced gene expression level of $L E A$ during PEG stress indicates the role of $L E A$ proteins in drought tolerance of rice seedlings. Increased expressions of $L E A$ under PEG stress conditions designate the significant role of $L E A$ in alleviating cellular damage due to dehydration (Sen et al. 2021). UV-B priming and re-priming significantly enhanced the gene expression of Group 3 $L E A$ proteins, leading to the retention of cellular functional integrity in rice seedlings (Fig. 6A). Group 3 LEA proteins prevent cell shrinkage due to excess water loss and thereby impart tolerance towards dehydration stress (Aslam et al. 2015). Heat shock proteins play an important role in protecting and repairing damaged proteins and membranes, protecting photosynthesis, and balancing the redox state of the cell (Asthir 2015). It was observed that Hsp90 expression was considerably enhanced in rice seedlings as a result of UV-B priming and re-priming finally leading to the improved PEG stress tolerance (Fig. 6B). It was also reported that $H s p 90$ provides drought stress tolerance in cassava by regulating abscisic acid and hydrogen peroxide content (Wei et al. 2020).

The present study proved that rice seedlings could form 'priming imprints' which makes seedlings more tolerant at their maximum potential on further stress exposure in the next generation. The efficient defense mechanism in UV-B-primed rice seedlings in $F_{1}$ generation is because of the retention of priming imprint which improved the tolerance towards PEG stress. DNA methylation patterns contribute towards the regulation of stress-responsive gene 
expression for developing intergenerational resistance as reported by Kuźnicki et al. (2019). Re-priming in the second generation resulted in the further boosting of innate tolerance potential indicating that this method can maximize the stress tolerance capacity of a plant. In this way, UV-B seed priming can boost the stress defense capacity, which can be utilized in further generations under challenging environmental conditions.

Conclusion: This study reveals that UV-B seed priming and re-priming improve the PEG stress tolerance potential of rice seedlings. UV-B seed priming alleviated the stress effects by enhancing relative gene expression of antioxidants and stress-related proteins. This leads to enhanced photosynthetic and respiratory activities in rice seedlings. The transgenerational priming memory retained in the seeds gets transferred to the offspring and re-priming in $\mathrm{F}_{1}$ generation further boosts this memory leading to low ROS contents. Therefore, UV-B of priming rice seeds can be used to boost and maximize the tolerance potential of a tolerant variety under challenging environmental conditions in the subsequent generations.

\section{References}

Ahmad M.A., Javed R., Adeel M. et al.: PEG 6000-stimulated drought stress improves the attributes of in vitro growth, steviol glycosides production, and antioxidant activities in Stevia rebaudiana Bertoni. - Plants 9: 1552, 2020.

Aslam M., Maqbool M.A., Cengiz R.: Mechanisms of drought resistance. - In: Drought Stress in Maize (Zea mays L.). Pp. 19-36, Springer, Cham 2015.

Asthir B.: Protective mechanisms of heat tolerance in crop plants. - J. Plant Interact. 10: 202-210, 2015.

Badawi G.H., Kawano N., Yamauchi Y. et al.: Over-expression of ascorbate peroxidase in tobacco chloroplasts enhances the tolerance to salt stress and water deficit. - Physiol. Plantarum 121: 231-238, 2004a.

Badawi G.H., Yamauchi Y., Shimada E. et al.: Enhanced tolerance to salt stress and water deficit by overexpressing superoxide dismutase in tobacco (Nicotiana tabacum) chloroplasts. Plant Sci. 166: 919-928, 2004b.

Bates L.S., Waldren R.P., Teare I.K.: Rapid determination of free proline for water studies. - Plant Soil 39: 205-207, 1973.

Begcy K., Mariano E.D., Lembke C.G. et al.: Overexpression of an evolutionarily conserved drought-responsive sugarcane gene enhances salinity and drought resilience. - Ann. Bot.London 124: 691-700, 2019.

Boguszewska-Mańkowska B., Pieczyński M., Wyrzykowska A. et al: : Divergent strategies displayed by potato (Solanum tuberosum L.) cultivars to cope with soil drought. - J. Agron. Crop Sci. 204: 13-30, 2018.

Bradford M.M.: A rapid and sensitive method for the quantification of microgram quantities of proteins utilizing the principle of protein-dye binding. - Anal. Biochem. 72: 248-254, 1976.

Calabrese E.J.: Hormesis: changing view of the dose-response, a personal account of the history and current status. - Mutat. Res. 511: 181-189, 2002.

Caldwell M.M.: Solar UV irradiation and the growth and development of higher plants. - In: Giese A.C. (ed.): Photophysiology: Current Topics in Photobiology and Photochemistry. Pp. 131-177. Academic Press, New York 1971.

Chen J.X., Wang X.F.: Guide to Plant Physiological Experiments.
Pp. 123-127. South China University of Technology Press, Guangzhou 2002.

Chen K., Arora R.: Priming memory invokes seed stresstolerance. - Environ. Exp. Bot. 94: 33-45, 2013.

Crisp P.A., Ganguly D., Eichten S.R. et al.: Reconsidering plant memory: Intersections between stress recovery, RNA turnover, and epigenetics. - Sci. Adv. 2: e1501340, 2016.

Dąbrowski P., Kalaji M.H., Baczewska A.H. et al.: Delayed chlorophyll $a$ fluorescence, MR 820, and gas exchange changes in perennial ryegrass under salt stress. J. Lumin. 183: 322-333, 2017.

Dąbrowski P., Pawluśkiewicz B., Baczewska A.H. et al.: Chlorophyll a fluorescence of perennial ryegrass (Lolium perenne L.) varieties under long term exposure to shade. Zemdirbyste 102: 305-312, 2015.

Doke N.: Involvement of superoxide anion generation in the hypersensitive response of potato tuber tissues to infection with an incompatible race of Phytophtora infestans and the hyphal wall components. - Physiol. Plant Pathol. 23: $345-$ $357,1983$.

Fatima A., Kataria S., Agrawal A.K. et al.: Use of synchrotron phase-sensitive imaging for the investigation of magnetopriming and solar UV-exclusion impact on soybean (Glycine max) leaves. - Cells 10: 1725, 2021.

Giannopolitis C.N., Ries S.K.: Superoxide dismutases: I. Occurrence in higher plants. - Plant Physiol. 59: 309-314, 1977.

Gill S.S., Tuteja N.: Reactive oxygen species and antioxidant machinery in abiotic stress tolerance in crop plants. - Plant Physiol. Bioch. 48: 909-930, 2010.

Halliwell B., Gutteridge J.M.C.: Free Radicals in Biology and Medicine. Pp. 905. Oxford University Press, USA 2015.

Hasanuzzaman M., Bhuyan M.H.M.B., Parvin K. et al.: Regulation of ROS metabolism in plants under environmental stress: A review of recent experimental evidence. - Int. J. Mol. Sci. 21: 8695, 2020.

Heath R.L., Packer L.: Photoperoxidation in isolated chloroplasts. I. Kinetics and stoichiometry of fatty acid peroxidation. Arch. Biochem. Biophys. 125: 189-198, 1968.

Heyneke E., Luschin-Ebengreuth N., Krajcer I. et al.: Dynamic compartment specific changes in glutathione and ascorbate levels in Arabidopsis plants exposed to different light intensities. - BMC Plant Biol. 13: 104, 2013.

Hussain S., Rao M.J., Anjum M.A. et al.: Oxidative stress and antioxidant defense in plants under drought conditions. - In: Hasanuzzaman M., Hakeem K., Nahar K., Alharby H. (ed.): Plant Abiotic Stress Tolerance. Pp. 207-219. Springer, Cham 2019.

Junglee S., Urban L., Sallanon H., Lopez-Lauri F.: Optimized assay for hydrogen peroxide determination in plant tissue using potassium iodide. - Am. J. Anal. Chem. 5: 730-736, 2014.

Kalaji H., Nalborczyk E.: Gas exchange of barley seedlings growing under salinity stress. - Photosynthetica 25: 197-202, 1991.

Kar M., Mishra D.: Catalase, peroxidase, and polyphenol oxidase activities during rice leaf senescence. - Plant Physiol. 57: 315-319, 1976.

Kaur G., Asthir B.: Molecular responses to drought stress in plants. - Biol. Plantarum 61: 201-209, 2017.

Kollöffel C.: Respiration rate and mitochondrial activity in the cotyledons of Pisum sativum during germination. - Acta Bot. Neerl. 16: 111-122, 1967.

Kuźnicki D., Meller B., Arasimowicz-Jelonek M. et al.: BABAinduced DNA methylome adjustment to intergenerational defense priming in potato to Phytophthora infestans. - Front. Plant Sci. 10: 650, 2019. 
Macovei A., Garg B., Raikwar S. et al.: Synergistic exposure of rice seeds to different doses of $\gamma$-ray and salinity stress resulted in increased antioxidant enzyme activities and genespecific modulation of TC-NER pathway. - BioMed Res. Int. 2014: 676934, 2014.

Mancinelli A.L., Yang C.P.H., Lindquist P. et al.: Photocontrol of anthocyanin synthesis: III. The action of streptomycin on the synthesis of chlorophyll and anthocyanin. - Plant Physiol. 55: 251-257, 1975.

Mirecki R.M., Teramura A.H.: Effects of ultraviolet-B irradiance on soybean: V. The dependence of plant sensitivity on the photosynthetic photon flux density during and after leaf expansion. - Plant Physiol. 74: 475-480, 1984.

Nakano Y., Asada K.: Hydrogen peroxide is scavenged by ascorbate-specific peroxidase in spinach chloroplasts. - Plant Cell Physiol. 22: 867-880, 1981.

Nayyar H., Gupta D.: Differential sensitivity of $\mathrm{C}_{3}$ and $\mathrm{C}_{4}$ plants to water deficit stress: association with oxidative stress and antioxidants. - Environ. Exp. Bot. 58: 106-113, 2006.

Pandey A.K., Gautam A.: Stress responsive gene regulation in relation to hydrogen sulfide in plants under abiotic stress. Physiol. Plantarum 168: 511-525, 2020.

Pandey V., Shukla A.: Acclimation and tolerance strategies of rice under drought stress. - Rice Sci. 22: 147-161, 2015.

Pogrzeba M., Rusinowski S., Sitko K. et al.: Relationships between soil parameters and physiological status of Miscanthus $\times$ giganteus cultivated on soil contaminated with trace elements under NPK fertilisation vs. microbial inoculation. - Environ. Pollut. 225: 163-174, 2017.

Pradhan B., Baral S., Patra S. et al.: Delineation of gamma irradiation $\left({ }^{60} \mathrm{Co}\right)$ induced oxidative stress by decrypting antioxidants and biochemical responses of microalga, Chlorella sp. - Biocatal. Agric. Biotechnol. 25: 101595, 2020.

Rapacz M., Sasal M., Kalaji H.M., Kościelniak J.: Is the OJIP test a reliable indicator of winter hardiness and freezing tolerance of common wheat and triticale under variable winter environments? - PLoS ONE 10: e0134820, 2015.

Rawat N., Singla-Pareek S.L., Pareek A.: Membrane dynamics during individual and combined abiotic stresses in plants and tools to study the same. - Physiol. Plantarum 171: 653-676, 2021

Reddy A.R., Chaitanya K.V., Vivekanandan M.: Drought-induced responses of photosynthesis and antioxidant metabolism in higher plants. - J. Plant Physiol. 161: 1189-1202, 2004.

Rossatto T., Amaral M.N., Benitez L.C. et al.: Gene expression and activity of antioxidative enzymes in rice plants, cv. BRS AG, under saline stress. - Physiol. Mol. Biol. Pla. 23: 865875, 2017.

Schmitt N., Dizengremel P.: Effect of osmotic stress on mitochondria isolated from etiolated mung bean and sorghum seedlings. - Plant Physiol. Bioch. 27: 17-26, 1989.

Seleiman M.F., Al-Suhaibani N., Ali N. et al.: Drought stress impacts on plants and different approaches to alleviate its adverse effects. - Plants 10: 259, 2021.

Semwal V.K., Khanna-Chopra R.: Reproductive sink enhanced drought induced senescence in wheat fertile line is associated with loss of antioxidant competence compared to its CMS line. - Physiol. Mol. Biol. Pla. 24: 591-604, 2018.

Sen A., Challabathula D., Puthur J.T.: UV-B priming of Oryza sativa seeds augments the innate tolerance potential in a tolerant variety more effectively toward $\mathrm{NaCl}$ and $\mathrm{PEG}$ stressors. - J. Plant Growth Regul. 40: 1166-1180, 2021.

Sen A., Puthur J.T.: Seed priming-induced physiochemical and molecular events in plants coupled to abiotic stress tolerance: an overview. - In: Hossain M.A., Liu F., Burritt D.J. et al. (ed.): Priming-Mediated Stress and Cross-Stress Tolerance in Crop Plants. Pp. 303-316. Academic Press, London 2020.

Sen A., Puthur J.T.: Halo- and UV-B priming-mediated drought tolerance and recovery in rice seedlings. - Plant Stress 2: 100011, 2021

Sheteiwy M.S., Gong D., Gao Y. et al.: Priming with methyl jasmonate alleviates polyethylene glycol-induced osmotic stress in rice seeds by regulating the seed metabolic profile. Environ. Exp. Bot. 153: 236-248, 2018.

Sohag A.A.M., Tahjib-Ul-Arif M., Brestič M. et al.: Exogenous salicylic acid and hydrogen peroxide attenuate drought stress in rice. - Plant Soil Environ. 66: 7-13, 2020.

Srivastava A., Strasser R.J., Govindjee: Differential effects of dimethylbenzoquinone and dichlorobenzoquinone on chlorophyll fluorescence transient in spinach thylakoids. J. Photoch. Photobio. B 31: 163-169, 1995.

Strasser R.J., Tsimilli-Michael M., Srivastava A.: Analysis of the chlorophyll $a$ fluorescence transient. - In: Papageorgiou G.C., Govindjee (ed.): Chlorophyll $a$ Fluorescence: A Signature of Photosynthesis. Advances in Photosynthesis and Respiration. Pp. 321-362. Springer, Dordrecht 2004.

Sytar O., Zivcak M., Bruckova K. et al.: Shift in accumulation of flavonoids and phenolic acids in lettuce attributable to changes in ultraviolet radiation and temperature. - Sci. Hortic.-Amsterdam 239: 193-204, 2018.

Tóth S.Z., Nagy V., Puthur J.T. et al.: The physiological role of ascorbate as photosystem II electron donor: protection against photoinactivation in heat-stressed leaves. - Plant Physiol. 156: 382-392, 2011.

Tuba Z., Saxena D.K., Srivastava K. et al:: Chlorophyll a fluorescence measurements for validating the tolerant bryophytes for heavy metal $(\mathrm{Pb})$ bio mapping. - Curr. Sci. 98: $1505-1508,2010$

Valenzuela-Avendaño J.P., Mota I.A.E., Uc G.L. et al.: Use of a simple method to isolate intact RNA from partially hydrated Selaginella lepidophylla plants. - Plant Mol. Biol. Rep. 23: 199-200, 2005.

Vozhehova R., Kokovikhin S., Lykhovyd P.V. et al.: Statistical yielding models of some irrigated vegetable crops in dependence on water use and heat supply. - J. Water Land Dev. 45: 190-197, 2020.

Wang X., Wang L., Shangguan Z.: Leaf gas exchange and fluorescence of two winter wheat varieties in response to drought stress and nitrogen supply. - PLoS ONE 11: e0165733, 2016.

Wei Y., Liu W., Hu W. et al.: The chaperone MeHsp90 recruits MeWRKY20 and MeCatalase1 to regulate drought stress resistance in cassava. - New Phytol. 226: 476-491, 2020.

Yamane K., Kawasaki M., Taniguchi M., Miyake H.: Correlation between chloroplast ultrastructure and chlorophyll fluorescence characteristics in the leaves of rice (Oryza sativa L.) grown under salinity. - Plant Prod. Sci. 11: 139-145, 2008.

Yin D., Chen S., Chen F. et al:: Morphological and physiological responses of two chrysanthemum cultivars differing in their tolerance to waterlogging. - Environ. Exp. Bot. 67: 87-93, 2009.

Zhang H., Xu N., Li X., Gu S.: Overexpression of 2-Cys PrX increased salt tolerance of photosystem II (PSII) in tobacco. Peer J. Preprints: e2500v1, 2016.

Zheng X.T., Yu Z.C., Tang J.W. et al.: The major photoprotective role of anthocyanins in leaves of Arabidopsis thaliana under long-term high light treatment: antioxidant or light attenuator? -Photosynth. Res. 149: 25-40, 2021.

(C) The authors. This is an open access article distributed under the terms of the Creative Commons BY-NC-ND Licence. 